\title{
Local continuous glial cell derived neurotrophic factor release using osmotic pump promotes parasympathetic nerve rehabilitation in an animal model of cavernous nerve injury induced erectile dysfunction
}

\author{
Huixi Li, Zhichao Zhang, Dong Fang, Yuan Tang, Jing Peng \\ Andrology Center, Department of Urology, Peking University First Hospital, Peking University, Beijing, China \\ Contributions: (I) Conception and design: H Li; (II) Administrative support: Z Zhang; (III) Provision of study materials or patients: H Li; (IV) \\ Collection and assembly of data: H Li, Z Zhang, D Fang, Y Tang; (V) Data analysis and interpretation: H Li, J Peng; (VI) Manuscript writing: All \\ authors; (VII) Final approval of manuscript: All authors. \\ Correspondence to: Huixi Li. No. A59, Di’anmen West Street, Xicheng District, Beijing 100009, China. Email: huixilee@hsc.pku.edu.cn.
}

\begin{abstract}
Background: Nerve injury-related erectile dysfunction (ED) is one of the types that respond poorly to conventional ED treatments. Our previous experiments have demonstrated the paracrine of various neurotrophic factors (NTFs) by stem cells or other treatment modalities as a potential mechanism in the recovery of nerve injury-related ED. Glial cell derived neurotrophic factor (GDNF) is one of the essential NTFs for the regeneration of nerve fibers, especially for parasympathetic nerves. The aim of this study is to explore if local continuous GDNF administration is beneficial for the functional and histological recovery of nerve injury induced ED.
\end{abstract}

Methods: Eight-week-old male Sprague-Dawley rats were used for this study. Rats were randomly grouped into 5: Sham surgery (Sham), bilateral cavernous nerve injury (BCNI) and placebo treatment, BCNI and $0.1 \mu \mathrm{g} / 100 \mu \mathrm{L}$ GDNF treatment (BCNI+GDNF 0.1), BCNI and $1 \mu \mathrm{g} / 100 \mu \mathrm{L}$ GDNF treatment (BCNI+GDNF 1), BCNI and $10 \mu \mathrm{g} / 100 \mu \mathrm{L}$ GDNF treatment (BCNI+GDNF 10). GDNF was administered using an osmotic pump technique which would deliver GDNF locally and continuously for 28 days without the need for external connections or frequent handling of animals. Recovery of sexual function, nerve fibers regeneration, and expression of neurotrophic receptors were examined and compared among groups after the treatment.

Results: Local continuous GDNF release treatment increased the average number of intromissions in the sexual behavior test and intracavernous pressure (ICP) in the erectile function test in a dose dependent manner. Osmotic pump implantation induced increased local GDNF concentration and mild inflammatory response. Gene expression of GDNF receptors in major pelvic ganglion (MPG) and nerve regeneration along the urethra were partially promoted by GDNF. These changes were associated with increased nerve fibers especially the parasympathetic nerve fibers in dorsal nerve of penis (DNP) in GDNF treated groups.

Conclusions: In conclusion, our project illustrated the promising effects of local continuous GDNF administration for the functional and histological recovery of nerve injury-induced ED.

Keywords: Glial cell derived neurotrophic factor (GDNF); osmotic pump; nerve injury; parasympathetic rehabilitation; erectile dysfunction (ED)

Submitted Jul 23, 2020. Accepted for publication Oct 28, 2020.

doi: $10.21037 /$ tau-20-1110

View this article at: http://dx.doi.org/10.21037/tau-20-1110 


\section{Introduction}

Erectile dysfunction (ED) as a common problem in the field of urology and andrology has huge negative effects on patients' quality of life $(1,2)$. Although multi-etiological factors have been found to be involved in the progression of ED (3), nerve damage and recovery have been proven to be a vital component in the development and management of ED (4). This has been proven in clinical scenarios as organic ED is found to be more frequent among the aging population, patients after pelvic surgery, patients with cardiovascular disease, and patients with diabetes, most of which involve nerve injury or degeneration. Meanwhile, ED patients with nerve damage usually respond poorly to conventional ED treatments $(5,6)$, such as phosphodiesterase 5 inhibitors (PDE5is), the widely prescribed medications for the "symptomatic treatment" of $\operatorname{ED}(7,8)$. Owing to the fact that none of the current ED interventions could fully "reverse" the pathological changes, especially the nerve damage in ED (9), the pursue to find curable treatment has been carried forward enthusiastically.

A complete neural network is the initiating and maintaining factor for normal erection, but nerve regeneration after injury is known for its slow speed and high uncertainty $(4,10)$. Meanwhile, cavernous nerve regeneration has its unique characteristics. After local nerve injury, sympathetic nerve fibers regrow more fast resulting in hyperinnervation, but parasympathetic nerve fibers which are key components to initiate and maintain nitric oxide (NO) production and erection status regrow much slower resulting in "autonomic imbalance" (11). In our previous animal experiments of nerve injury-related $\operatorname{ED}(3,11)$, some of the novel interventions we investigated such as the low energy shock wave therapy $(3,12)$ and stem cells products $(5,13)$ has been shown to facilitate the local secretion of various neurotrophic factors (NTFs). We speculate that one or more NTFs might be the underlying mechanisms for accelerating nerve regeneration and erectile function recovery in these interventions. However, due to the lack of research of "multicomponent" NTFs, we haven't found any specific relationships that targeted the erection related nerve regeneration (10).

Glial cell derived neurotrophic factor (GDNF) was one of the up-regulated NTFs associated with these interventions as mentioned above. Tremendous works of literature have shown the vital role of GDNF superfamily in the differentiation, regeneration, and maintaining of pelvic parasympathetic neural networks, especially through the GDNF-GDNF receptor (GFR) $\alpha 1$-Ret pathway and neurturin (NTN)-GFR $\alpha 2$-Ret pathway (14-18). Meanwhile, the nerve growth factor (NGF)-neurotrophic receptor tyrosine kinase type 1 (Ntrk1) pathway has been shown to mainly promote sympathetic regeneration (19). Based on these findings, we hypothesized that GDNF might be beneficial for nerve regeneration especially for parasympathetic nerve regeneration and "correction" of "autonomic imbalance" after cavernous nerve injury. In this project, we tried to test this hypothesis using a specially designed GDNF administration system in an animal model of bilateral cavernous nerve injury (BCNI). In order to create a more stable long-term GDNF enrich local environment, different levels of GDNF were administered locally using an osmotic pump which could deliver GDNF solution continuously and accurately for up to 4 weeks without the need for external connections or frequent handling of animals. Sexual behavior tests and erectile function tests were conducted after treatment. Expression of NTF receptors including GFRs and Ntrk1 were examined and parasympathetic nerve regeneration was investigated. This experiment would give us a preliminary answer of whether precise GDNF enrich local environment is beneficial for the recovery of "autonomic balance" and sexual function after BCNI. We present the following article in accordance with the ARRIVE reporting checklist (available at http://dx.doi.org/10.21037/tau-20-1110).

\section{Methods}

\section{Experimental design}

Experiments were performed under a project license (No.: 201875) granted by institutional ethics board of animal care and use committee of Peking university first hospital, in compliance with national guidelines for the care and use of animals. A total of fifty 8 -week-old sexually mature male Sprague-Dawley rats and fifty 12 -week-old female Sprague-Dawley rats were used for this study. Rats were kept in $12 \mathrm{~h}$ light/12 h dark lighting cycle with food and water freely available. Male rats were randomly grouped into 5 ( $\mathrm{n}=10$ each): Sham surgery (Sham), BCNI and placebo treatment, BCNI and $0.1 \mu \mathrm{g} / 100 \mu \mathrm{L}$ GDNF treatment (BCNI+GDNF 0.1), BCNI and $1 \mu \mathrm{g} / 100 \mu \mathrm{L}$ GDNF treatment (BCNI+GDNF 1), BCNI and $10 \mu \mathrm{g} / 100 \mu \mathrm{L}$ GDNF treatment (BCNI+GDNF 10). After 4 weeks of local continuous GDNF release treatment, all male rats underwent unpaced sexual behavior test with 
female rats and erectile function measurement. The male rats were sacrificed and the blood, serum, peritoneal lavage fluid (PLF), major pelvic ganglion (MPG), urethral tissue, and penile tissue were collected for histology (immunofluorescence staining), laboratory test (ELISA, White blood cell, or WBC count) and molecular studies (Western blot, real time-PCR).

\section{Animal surgery and osmotic pump implantation}

To produce BCNI, the rats were weighed and anesthetized with an intraperitoneal injection of pentobarbital sodium. The bladder and prostate were exposed via a midline abdominal incision, and the MPGs and cavernous nerves were identified posterolateral to the prostate. Cavernous nerves were crushed by applying hemostatic forceps (RS7116, Roboz, Gaithersburg, Germany) for $2 \mathrm{~min}$. The cavernous nerve injury point was $5 \mathrm{~mm}$ distal to the MPG. The sham surgery was performed in exactly the same way except no nerves were crushed. Before closing the abdominal wall, an osmotic pump (Alzet micro-osmotic pump, model 1004) filling with specific dose of GDNF (Merck, G1777) was implanted close to the prostate in the pelvic cavity (Figure 1A). GDNF was dissolved in normal saline and was pre-injected in the pump at doses of $0 \mu \mathrm{g} / 100 \mu \mathrm{L}$, $0.1 \mu \mathrm{g} / 100 \mu \mathrm{L}, 1 \mu \mathrm{g} / 100 \mu \mathrm{L}, 10 \mu \mathrm{g} / 100 \mu \mathrm{L}$ for rats in groups of BCNI, BCNI+GDNF 0.1, BCNI+GDNF $1, \mathrm{BCNI}+\mathrm{GDNF} 10$ respectively. The osmotic pump should release the GDNF solution locally at a rate around $0.11 \mu \mathrm{L} /$ hour for up to 28 days.

\section{Unpaced sexual behavior tests}

Tests were conducted during the light-on period to provide a behaviorally sluggish baseline condition. Female rats were purchased when the sexual behavior tests were going to be done and they were brought to sexual receptivity via intraperitoneal injection of estradiol benzoate $(50 \mathrm{mg} / \mathrm{animal})$ at $48 \mathrm{~h}$ and progesterone $(0.5 \mathrm{mg} / \mathrm{animal})$ at $10 \mathrm{~h}$ before sexual behavior test. Females were kept in the same room and fed with the same food and water as the males. All 10 male rats in each group were put into separate cages $(27 \mathrm{~cm} * 50 \mathrm{~cm}) 5 \mathrm{~min}$ before the start of the test to let them explore the arena before the female was introduced. Each female rat was then randomly paired with a male rat in the same cage. In this unpaced laboratory setting, male rats largely controlled sexual activities because female rats were unable to escape in such a small enclosure, which differed from wild or paced conditions. For each group, the test started at $11.00 \mathrm{AM}$ and ended at 3.00 PM. During the $4 \mathrm{~h}$ test, a camera was placed in front of the 10 cages and all activities of the 10 pairs were recorded. The videotapes were viewed and recorded by double-blinded researchers. Four activity types were recorded: chasing, mounting, intromission, and ejaculation. The definitions of sexual behaviors were as follows: Chasing: Pursuit to catch the female, trying to make contact to get the female interested; Mounting: Mounting with pelvic thrusting, but without vaginal penetration; Intromission: Mounting with vaginal penetration, genital licking or grooming after pelvic thrusting; Ejaculation: Presence of repeated deep forward thrust ( $\mathrm{T}+$ or $\mathrm{T}-)$ after vaginal penetration and/or presence of copulatory plug ( $\mathrm{P}+$ or $\mathrm{P}-)$ the second day. Ejaculation was judged based on the following rules. T-P-: No repeated deep forward thrust was recorded and no copulatory plug was found (indicating no ejaculation happened); $\mathrm{T}+\mathrm{P}-$ : Repeated deep forward thrust was recorded but no copulatory plug was found (indicating ejaculation might have happened); $\mathrm{T}+\mathrm{P}+$ : Repeated deep forward thrust was recorded and copulatory plug was found (indicating ejaculation did happen); T-P+: No repeated deep forward thrust was recorded but copulatory plug was found (indicating early ejaculation might have happened).

\section{Erectile function evaluation}

Under anesthesia, the MPG and cavernous nerves of the rat were exposed via a midline laparotomy. The corpora cavernosum of the penis was cannulated with a 25 -gauge butterfly needle filled with heparin $(250 \mathrm{U} / \mathrm{mL})$ via insertion at the crura. The cannula was connected to a pressure transducer (Biopac 16, CA, USA) for continuous assessment and recording of intracavernous pressure (ICP). Mean arterial pressure (MAP) was recorded continuously as previously described $(3,11)$. The left carotid artery was exposed and separated. A 25 -gauge butterfly needle filled with heparin $(250 \mathrm{U} / \mathrm{mL})$ was inserted into the carotid artery. The needle was connected to the pressure transducer through a PE-50 tube. The stimulus parameters for cavernous nerve were $1.5 \mathrm{~mA}, 20 \mathrm{~Hz}$, pulse width $0.2 \mathrm{~ms}$, and duration of $50 \mathrm{~s}$. The maximum increase in ICP for three stimuli per side for each animal was selected for statistical analysis. The rats without successful ICP recording due to technique issues were not involved in the statistical analysis. 
A
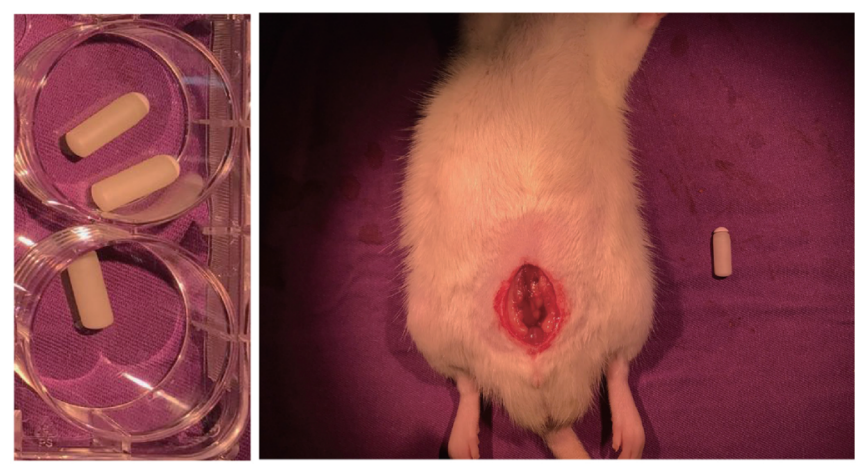

C

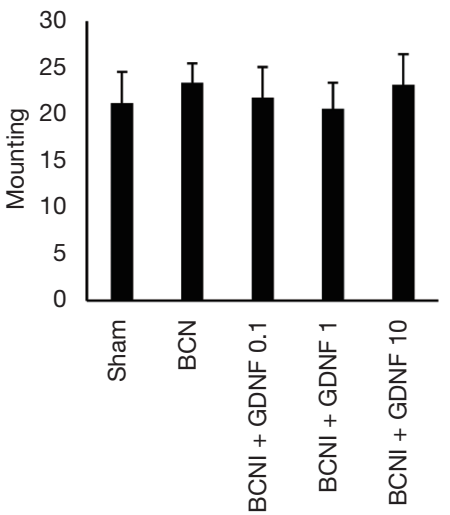

\section{B}

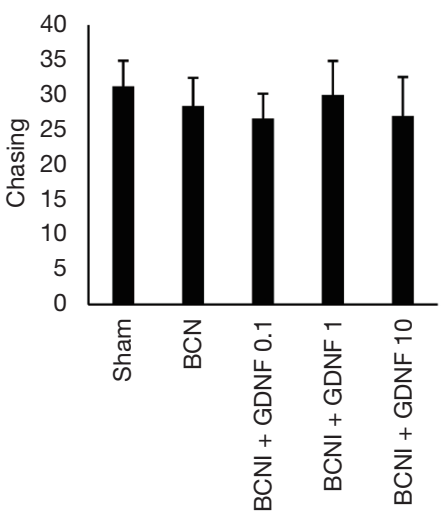

E

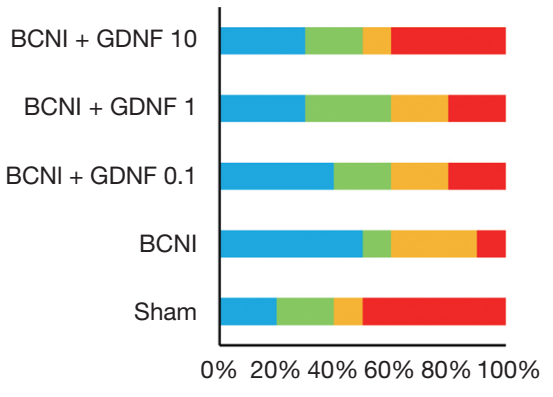

$\because \mathrm{T}-\mathrm{P}-\approx \mathrm{T}+\mathrm{P}-\backsim \mathrm{T}-\mathrm{P}+\approx \mathrm{T}+\mathrm{P}+$

Figure 1 Influence of local continuous GDNF release on sexual behavior. (A) Photos during the procedure of osmotic pump implantation. (B-D) Average umbers of chasing (B, $\mathrm{n}=8$ each), mounting (C, $\mathrm{n}=8$ each), and intromission ( $\mathrm{D}, \mathrm{n}=8$ each) in each rat. (E) Calculation of the percentage of rats with ejaculation based on presence of repeated deep forward thrust ( $\mathrm{T}+$ or $\mathrm{T}-)$ after vaginal penetration and presence of copulatory plug $(\mathrm{P}+$ or $\mathrm{P}-)$ the second day $(\mathrm{n}=10$ each). Data are presented as mean \pm STD or percentage. BCNI, bilateral cavernous nerve injury; GDNF, glial cell derived neurotrophic factor. *, $\mathrm{P}<0.05$ compared to Sham; ${ }^{*}, \mathrm{P}<0.05$ compared to BCNI.

\section{Laboratory test of WBC count and GDNF concentration}

Blood samples were collected in EDTA prewashed EP tubes for WBC count and regular EP tubes for serum collection. PLF was collected just before the laparotomy procedure during ICP recording as following steps: cut the outer skin of the peritoneum and gently pull it back to expose the inner skin lining the peritoneal cavity; inject $2 \mathrm{~mL}$ of normal saline into the peritoneal cavity using a 27 -gauge needle; gently massage the peritoneum, insert a 25 -gauge needle, bevel up, attached to a $5 \mathrm{~mL}$ syringe in the peritoneum and collect the fluid while moving the tip of the needle gently to avoid clogging by the fat tissue or other organs. WBC count in blood and PLF was calculated using an automatic blood analyzer (sysmex XE-2100). GDNF quantification in serum and PLF was measured using enzyme-linked immunosorbent assay (ELISA) kits according to the manufacturer's protocol (ab213901, Abcam).

\section{Histological analysis}

Urethral and penile tissue was freshly harvested and fixed and immunofluorescence staining was performed as previously described (3). The primary antibodies included anti-neurofilament (NF; 1:500; ab8135, Abcam), antityrosine hydroxylase (TH; 1:200; AB152, Millipore, Bedford, MA, USA), anti-vesicular acetylcholine transporter 
(VAChT; 1:200, ABN100, Millipore, Bedford, MA, USA). Secondary antibodies used included Alexa-488and Alexa-594-conjugated antibodies (1:500; Invitrogen). Smooth muscle in urethral tissue was stained by Alexa- 488 conjugated phalloidin (1:400; Invitrogen). Nuclei were stained with 40,6-diamidino-2-phenylindole (DAPI; Invitrogen). Image analysis was performed by computerized densitometry (K pixel number of integrated optical density) using Image-Pro Plus 5.1 (Media Cybernetics, Silver Spring, MD, USA).

\section{Real-time quantitative reverse transcription-PCR}

Fresh MPG tissue was immediately homogenized in TRIzol reagent followed by isolation of total RNA. cDNA was synthesized from the RNA using a Super Script III cDNA synthesis kit with random hexamer primers. Expression of the following NTF receptors genes was analyzed: Ntrk1 (GTCTGGTGGGTCAGGGACTA C A C A C AT C A C T C T C G G T GCT), GFR $\alpha 1$ ( A G C T G C A G C A C C A A G T A C C G C G C T T G G C C G G A A C C T T G T C GA A G), GFR $\alpha 2$ (GCTGTGTGCGGCTGAATCCAAC TATACTCGCTGGGCACACGGTC) and GAPDH (AG GTCGGTGTGAACGGATTTGTGTAGACCATGTAG TTGAGGTCA). Quantitative PCR was performed using the SYBR Green PCR Master kit with an ABI Prism 7500 Sequence Detection System (Applied Biosystems, Foster City, CA, USA).

\section{Western blotting}

Protein isolation and Western blot were conducted as previously reported (11). A total of $20 \mathrm{mg}$ protein was loaded for each sample. The primary antibodies used in Western blot were anti-tyrosine hydroxylase (TH, 1:500, AB152, Millipore, Bedford, MA, USA), anti-vesicular acetylcholine transporter (VAChT, 1:500, ABN100, Millipore, Bedford, MA, USA) and $\beta$-actin (1:1,000, ab8227; Abcam). After incubation with the secondary antibody, the resulting images were analyzed with ChemiImager 4000 (Alpha Innotech Corp., San Leandro, CA, USA) to determine the integrated density value of each protein band.

\section{Statistical analysis}

Results were analyzed using Prism 5 (GraphPad Software, San Diego, CA, USA) and are expressed as mean \pm standard deviations (SD). Multiple groups were compared by using one-way analysis of variance followed by the Tukey Kramer test for post-hoc comparisons (five variables). Statistical significance was set at $\mathrm{P}<0.05$. Numbers analyzed in each group: ejaculation percentage: 10/10; ICP: rats without successful ICP recording were not involved, Sham (8/10), BCNI (7/10), BCNI+GDNF 0.1 (7/10), BCNI+GDNF $1(8 / 10)$, BCNI+GDNF 10 (8/10); Western blot: 6 repeated tests with each sample randomly chosen from the corresponding group; all the other data: 8/10 (randomly chosen from corresponding group).

\section{Results}

\section{Influence of local continuous GDNF release on sexual bebavior}

All rats were healthy and active and no adverse events were recorded. Chasing was the most frequent sexual behavior, especially in the initial stage after the presentation of a female, followed by mounting, intromission, ejaculation in descending order. The average numbers of chasing and mounting were around similar levels among groups $(\mathrm{P}>0.05)$ indicating that the libido of male rats was not significantly affected by BCNI or GDNF administration (Figure 1B,C). Intromission was judged according to the duration and observation of genital licking after thrusting. BCNI caused a decrease in the average number of intromissions from 8 times per rat to 4 times per rat $(\mathrm{P}=0.0064)$. Local continuous GDNF release treatment increased the average number of intromissions in a dosage dependent manner and significant change happened at the dosage of $10 \mu \mathrm{g} / 100 \mu \mathrm{L}$ with an average number of intromissions recorded at 6.6 times per rat $(\mathrm{P}=0.029)$ indicating partial recovery of penile erectile function (Figure 1D). The percentage of rats with confirmed ejaculation $(\mathrm{T}+\mathrm{P}+$ and $\mathrm{T}-\mathrm{P}+)$ was $60 \%$ in Sham group. After BCNI, this percentage was $40 \%$ with $3 / 4$ of them might be early ejaculation (T-P+). The percentage of confirmed ejaculation $(\mathrm{T}+\mathrm{P}+$ and $\mathrm{T}-\mathrm{P}+)$ in GDNF treated groups are $40-50 \%$, but with lower rates of early ejaculation (T-P+, 10-20\%, Figure 1E).

\section{Local continuous GDNF release treatment improves erectile function after $B C N I$}

To further investigate the effect of GDNG on erectile function recovery, erectile hardness was measured by ICP and MAP recording with cavernous nerve stimulation under 
A

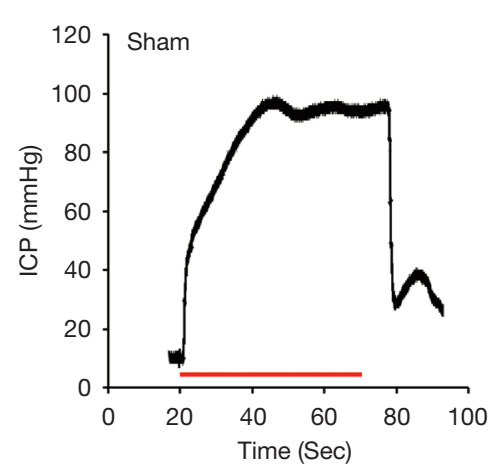

D

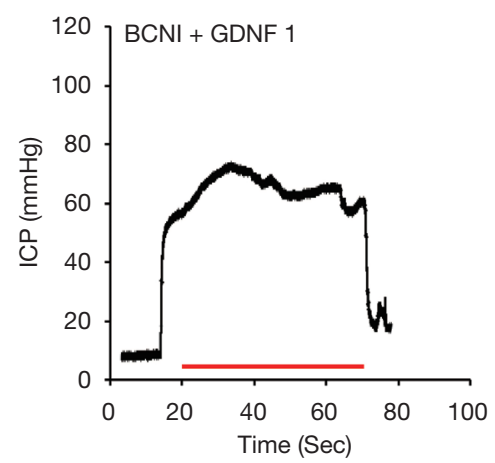

B

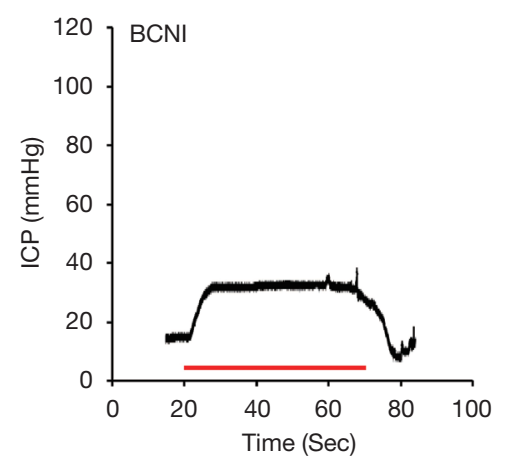

$\mathrm{E}$

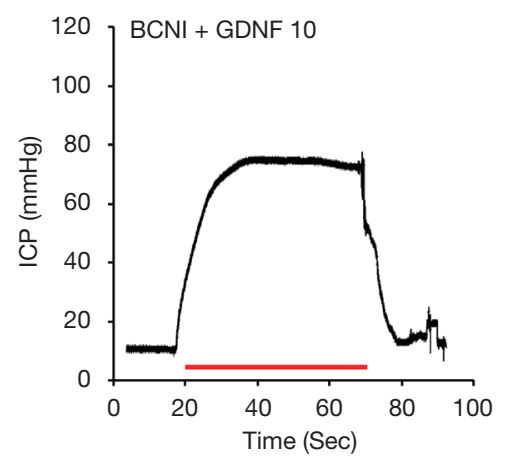

C

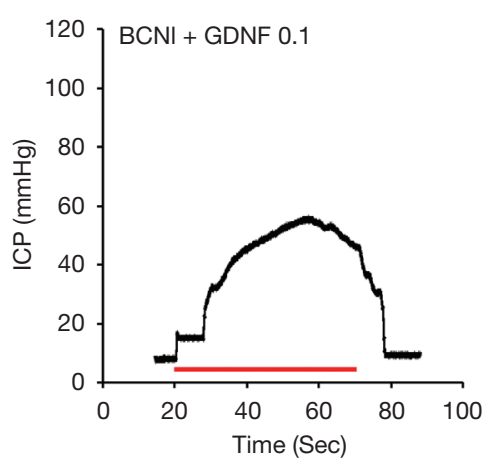

$\mathrm{F}$

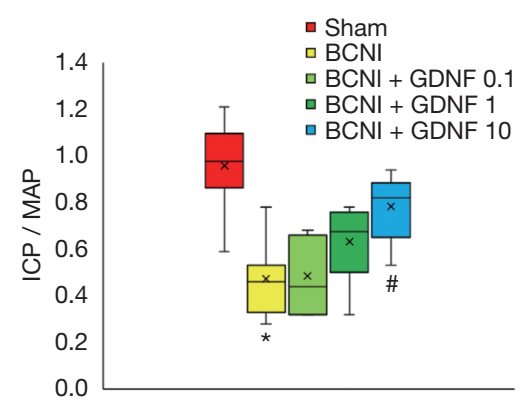

Figure 2 Local continuous GDNF release treatment improves erectile function after BCNI. (A-E) Representative ICP recordings for the experimental groups of Sham (A, n=8), BCNI (B, n=7), BCNI+GDNF 0.1 (C, n=7), BCNI+GDNF 1 (D, n=8), BCNI+GDNF 10 (E, n=8). The colored bar denotes the 50-s cavernous electrical stimulation. (F) Analysis of the ratio of ICP to MAP. Data are presented as mean with quartile and full range. BCNI, bilateral cavernous nerve injury; GDNF, glial cell derived neurotrophic factor; ICP, intracavernous pressure; MAP, mean arterial pressure. * $\mathrm{P}<0.05$ compared to Sham; \#, $\mathrm{P}<0.05$ compared to BCNI.

anesthesia. The sham group exhibited normal ICP curves and high ICP/MAP ratios $(0.96 \pm 0.19)$. BCNI consistently resulted in ED with $\mathrm{ICP} / \mathrm{MAP}$ ratios of $0.47 \pm 0.16$ $(\mathrm{P}=0.0002)$. Recovery of erectile function to varying degrees was observed in the BCNI+GDNF $0.1(0.49 \pm 0.15, \mathrm{P}=0.87)$, $\mathrm{BCNI}+\mathrm{GDNF} 1(0.63 \pm 0.16, \mathrm{P}=0.08), \mathrm{BCNI}+\mathrm{GDNF} 10$ $(0.78 \pm 0.14, \mathrm{P}=0.002)$ groups as reflected by higher ICP/ MAP ratios in response to cavernous nerve electrical stimulus compared to the BCNI group (Figure 2, Figure S1).

\section{Osmotic pump implantation induced increased local GDNF concentration and WBC count}

In order to investigate the distribution of the administered GDNF. The concentrations of GDNF in serum and PLF were measured (Figure 3A,B). There was no significant difference of GDNF concentration in serum among groups
$(\mathrm{P}>0.05$, Figure $3 B)$. The concentrations of GDNF in PLF were significantly higher in BCNI+GDNF $0.1(8.45 \pm$ $2.88 \mathrm{pg} / \mathrm{mL}, \mathrm{P}=0.02), \mathrm{BCNI}+\mathrm{GDNF} 1(9.85 \pm 3.53 \mathrm{pg} / \mathrm{mL}$, $\mathrm{P}=0.01), \mathrm{BCNI}+\mathrm{GDNF} 10(12.97 \pm 2.59 \mathrm{pg} / \mathrm{mL}, \mathrm{P}=0.0001)$ groups compared to the Sham group $(4.33 \pm 0.83 \mathrm{pg} / \mathrm{mL})$. The difference of GDNF concentration in PLF between the BCNI group and the Sham group was not significant (Figure 3A). These results indicated that administered GDNF mainly played its role locally in the peritoneal/pelvic cavity. Any foreign body implantations may cause local or systemic infection or inflammation. Although none of the rats illustrated behavior or gross pathological evidence of infection, we still examined the WBC count locally and systemically. Osmotic pump implantation induced slightly increased WBC counts in PLF about 22-27\% compared to the Sham group $(\mathrm{P}>0.05$, Figure $3 C)$ indicating mild local inflammatory response might have happened. The WBC 
A

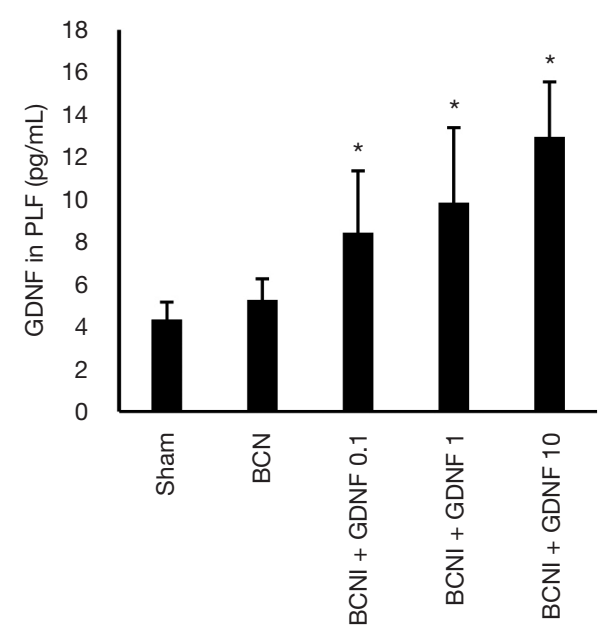

C

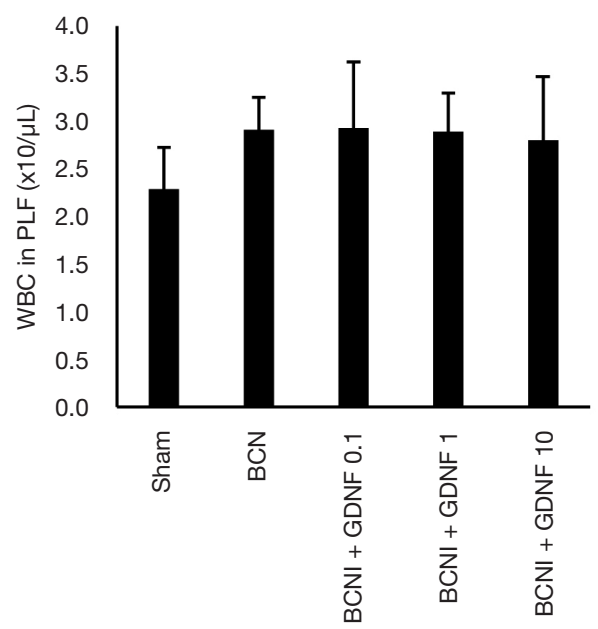

B

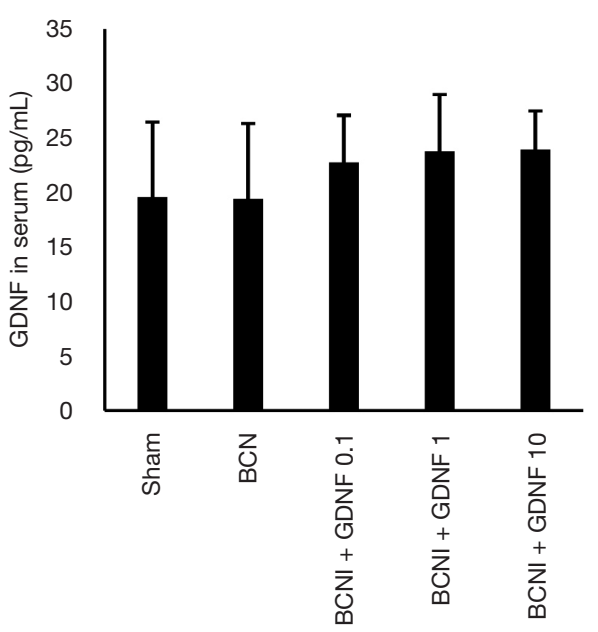

D

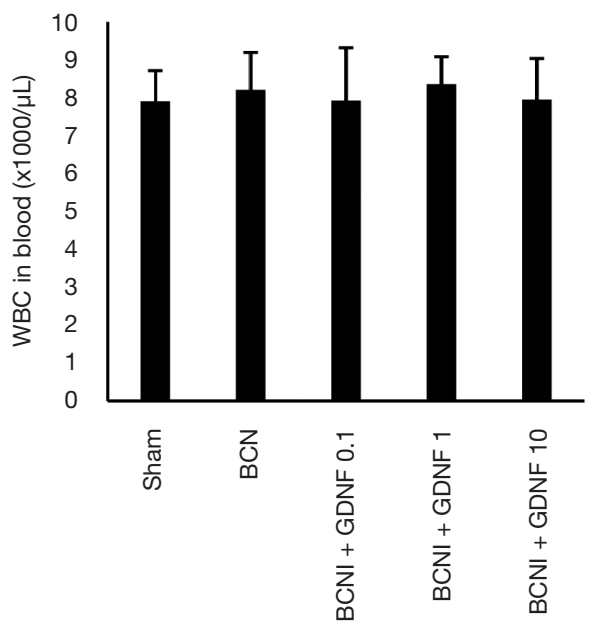

Figure 3 Osmotic pump implantation induced increased local GDNF concentration and WBC count. (A,B) Average GDNF concentration measured by ELISA in PLF (A, n=8 each) and serum (B, n=8 each) after treatment. (C,D) Average number of WBC in PLF (C, n=8 each) and blood $(\mathrm{D}, \mathrm{n}=8$ each) after treatment. Data are presented as mean \pm STD. BCNI, bilateral cavernous nerve injury; GDNF, glial cell derived neurotrophic factor; PLF, peritoneal lavage fluid; WBC, white blood cell. *, $\mathrm{P}<0.05$ compared to Sham.

counts in blood were not significantly varied among groups $(\mathrm{P}>0.05$, Figure 3D).

\section{Changes of neurotrophic receptor in MPG influenced by GDNF administration}

To explore the influence of GDNF release treatment on the local expression of neurotrophic receptors that are related to the regeneration of the autonomic nervous system, we examined the gene expression level of Ntrk1, GFR $\alpha 1$ and GFR $\alpha 2$ related to GAPDH in MPG using Real-time quantitative reverse transcription-PCR. The expression of Ntrk1 slightly increased after BCNI indicating potential sympathetic over-growth. The administration of GDNF didn't alter the expression of Ntrk1 significantly (Figure 4A). After BCNI, the gene expression of GFR $\alpha 1$ and GFR $\alpha 2$ are 

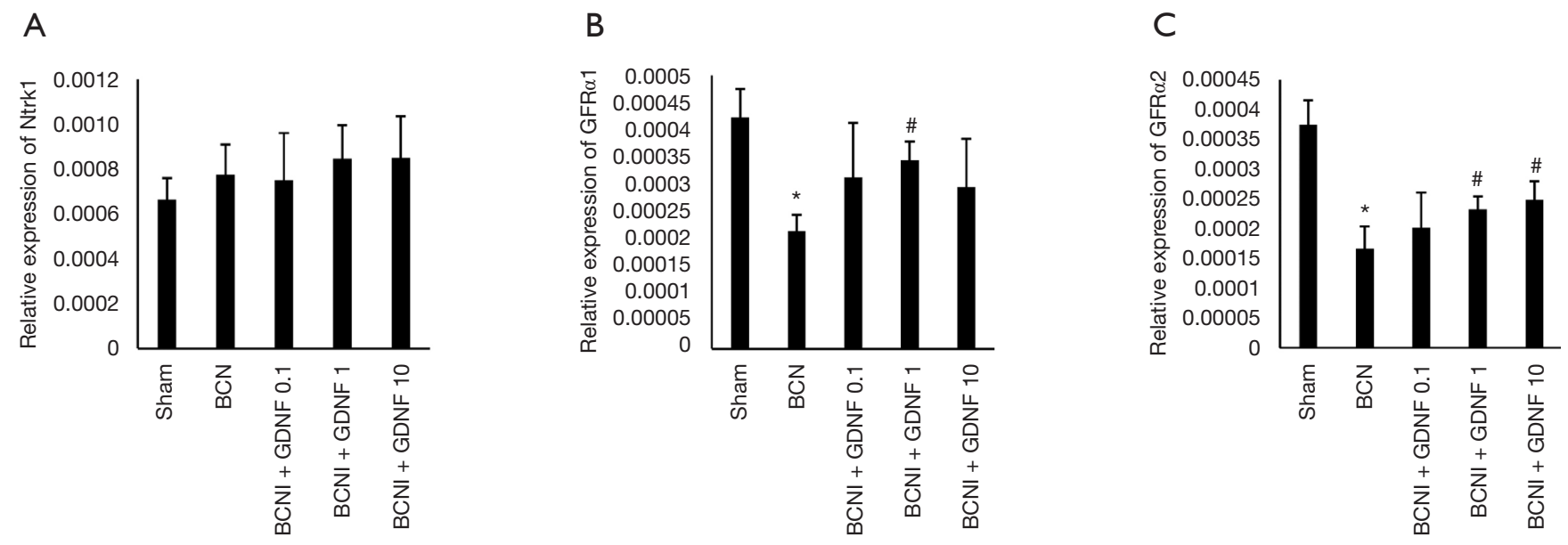

Figure 4 Changes of neurotrophic receptor in major pelvic ganglion (MPG) influenced by GDNF administration. (A-C) Relative expression of Ntrk1 (A, n=8 each), GFR $\alpha 1$ (B, n=8 each) and GFR $\alpha 2$ (C, n=8 each) measured by RT-PCR. Data are presented as mean \pm STD. BCNI, bilateral cavernous nerve injury; GDNF, glial cell derived neurotrophic factor; Ntrk, neurotrophic receptor tyrosine kinase; GFR, glial cell derived neurotrophic factor receptor. * $\mathrm{P}<0.05$ compared to Sham; ${ }^{*}, \mathrm{P}<0.05$ compared to BCNI.

decreased $(\mathrm{P}<0.05)$. GDNF administration increased the gene expression of GFR $\alpha 1$ and GFR $\alpha 2$ which suggesting the regeneration of parasympathetic nerve fibers (Figure 4B,C). The expression of GFR $\alpha 1$ was more promoted by GDNF at the $\mathrm{BCNI}+\mathrm{GDNF} 1$ group $(\mathrm{P}=0.0002$ compared to BCNI group). Higher level of GDNF (BCNI+GDNF 10) didn't induce more expression of GFR $\alpha 1$ possibly indicating negative feedback between NTF and receptor. The increased expressions of GFR $\alpha 2$ promoted by GDNF administration however, were in a dose dependent manner $(\mathrm{P}=0.01$ and 0.005 respectively in BCNI+GDNF 1 and BCNI+GDNF 10 groups compared to BCNI group) simply reflecting the increased total amount of parasympathetic nerve fibers in MPG.

\section{Nerve regeneration along the urethra}

Cavernous nerve fibers are believed to travel from MPG along the external surface of urethra and join with the internal pudendal nerve at the crus penis to form the dorsal nerve of penis (DNP). In order to examine the nerve rehabilitation of cavernous nerve fibers, urethral tissue was harvested and nerve fibers stained by neurofilament (NF) were examined and compared at different levels (upper $1 / 3$ of urethra and lower $1 / 3$ urethra, Figure $5 A, B$ ). The amount changes of $\mathrm{NF}+$ nerve fibers in the upper $1 / 3$ urethra were not significant among groups indicating animals do have some intrinsic nerve regeneration ability. Nerve fibers in lower $1 / 3$ urethra were more influenced by BCNI or GDNF administration indicating various regeneration ability over the longer regrowth route (Figure 5B,C). Nerve injury decreased $\mathrm{NF}+$ nerve fibers, especially at the lower $1 / 3$ urethra $(\mathrm{P}=0.01)$. The amount of $\mathrm{NF}+$ nerve fibers at lower $1 / 3$ urethra increased in a dose dependent manner after GDNF administration ( $\mathrm{P}=0.02$ in $\mathrm{BCNI}+\mathrm{GDNF} 10$ groups compared to the BCNI group).

\section{Regrowth of parasympathetic nerve was promoted by GDNF administration}

To investigate the balance of parasympathetic and sympathetic nerve fibers in penile tissue, DNP was examined by the staining of either TH a sympathetic nerve marker or VAChT a parasympathetic nerve marker (Figure $6 A$ ). After BCNI, overgrowth of sympathetic nerve or TH+ nerve fibers was robust as previously reported (11). BCNI caused a significant damage to the parasympathetic nerves or VAChT+ nerve fibers that are not fully recovered until 4 weeks later. Local GDNF release treatment promoted the regeneration of parasympathetic nerve fibers in a dose dependent manner. Increased VAChT expression in the treatment groups was further confirmed with Western blot using the protein lysates from penile tissue. The ratio of VAChT expression to TH expression was increased to about $2-3$ times in the BCNI+GDNF 1 and BCNI+GDNF 10 groups compared to the $\mathrm{BCNI}$ group $(\mathrm{P}=0.0003$ for 


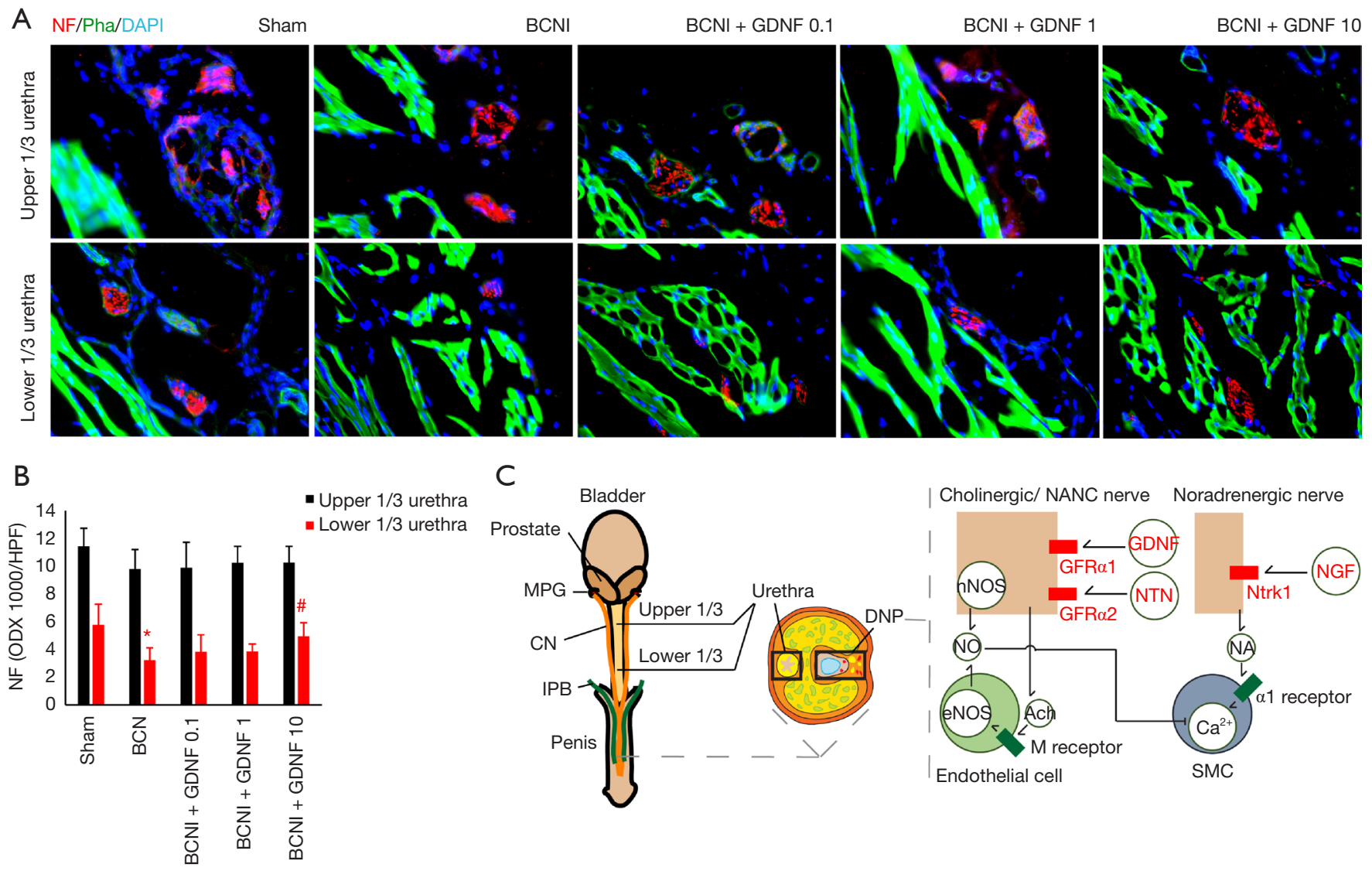

Figure 5 Nerve regeneration along the urethra. (A) Representative immunofluorescence staining of upper $1 / 3$ urethra and lower $1 / 3$ urethra for NF. Original magnification is 400x. (B) Average of OD amount of NF ( $\mathrm{n}=8$ each). (C) A scheme of local anatomy of rats and representative NTFs and receptors mentioned in this manuscript. Data are presented as mean \pm STD. BCNI, bilateral cavernous nerve injury; GDNF, glial cell derived neurotrophic factor; NTN, neurturin; NGF, nerve growth factor; NF, neurofilament; Pha, phalloidin; DAPI, 40,6-diamidino-2-phenylindole; OD, optical density; HPF, high power field; MPG, major pelvic ganglion; CN, cavernous nerve; IPB, internal pudendal bundle; DNP, dorsal nerve of penis; NANC, non-adrenergic non-cholinergic; nNOS, neuronal nitric oxide synthase; eNOS, endothelial nitric oxide synthase; NO, nitric oxide; Ntrk, neurotrophic receptor tyrosine kinase; GFR, glial cell derived neurotrophic factor receptor; Ach, acetylcholine; NA, noradrenalin; SMC, smooth muscle cell. *, $\mathrm{P}<0.05$ compared to Sham; * $\mathrm{P}<0.05$ compared to BCNI.

both, Figure $6 B, C)$. All these data supported the idea that GDNF administration promotes nerve regeneration from MPG, along the urethra, and finally leads to increased nerve fibers especially the parasympathetic nerve fibers in DNP and cavernosum.

\section{Discussion}

In this project, we showed that local continuous GDNF administration was beneficial for the functional and histological recovery of cavernous nerve injury-induced
ED. In fact, the whole male sexual response which includes sexual arousal, erection, emission, and ejaculation is precisely orchestrated by multiple levels of neurons $(20,21)$. Sexual arousal is usually stimulated by local tactile sensation or special senses. The complex conversation among cerebral cortex, limbic system, and hypothalamus finally converts into an integrated output that transmits through the spinal cord and parasympathetic nerve fibers to induce NO production and smooth muscle cell relaxation in cavernosum which finally leads to penile erection (Figure 5C) (22,23). Emission and ejaculation which 
A Sham $\mathrm{BCNI}$ $\mathrm{BCNI}+\mathrm{GDNF} 0.1$ $\mathrm{BCNI}+\mathrm{GDNF} 1$ $\mathrm{BCNI}+$ GDNF 10
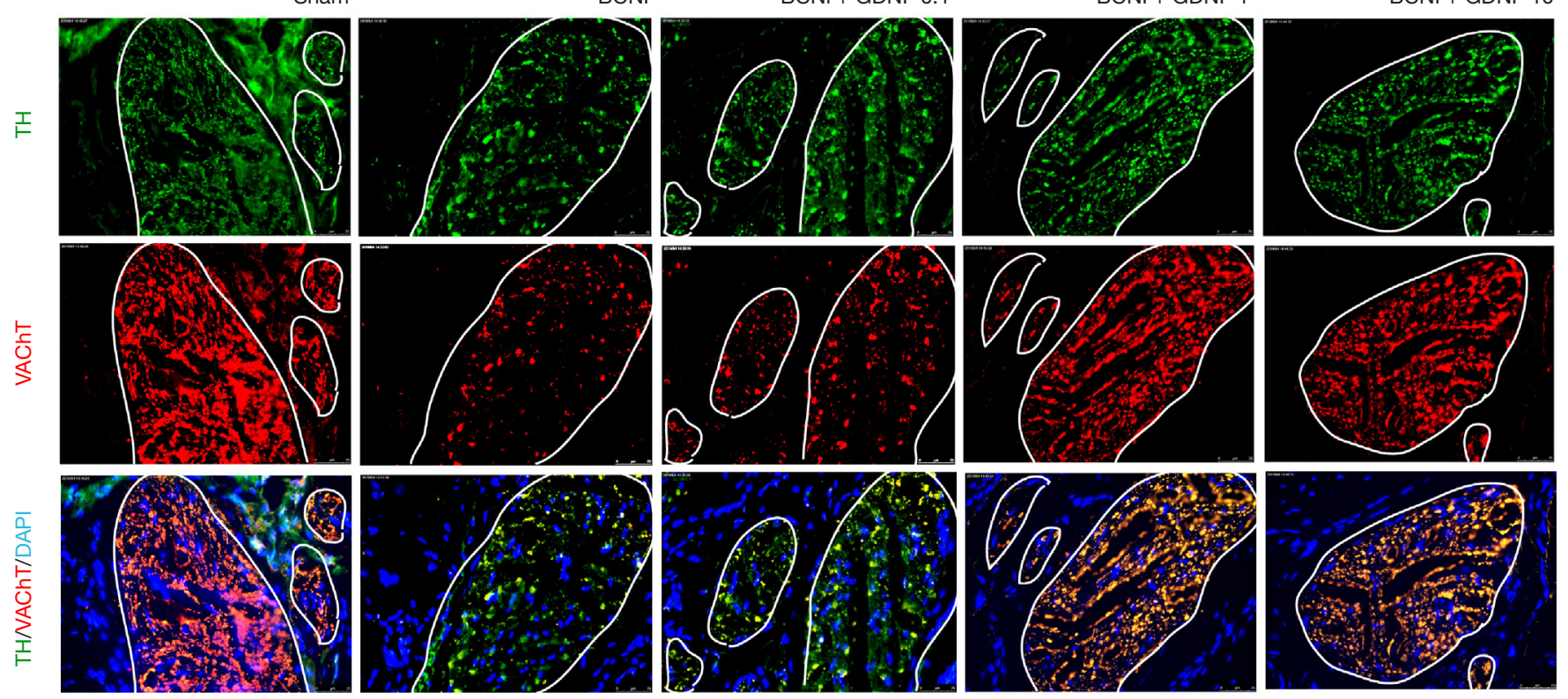

B

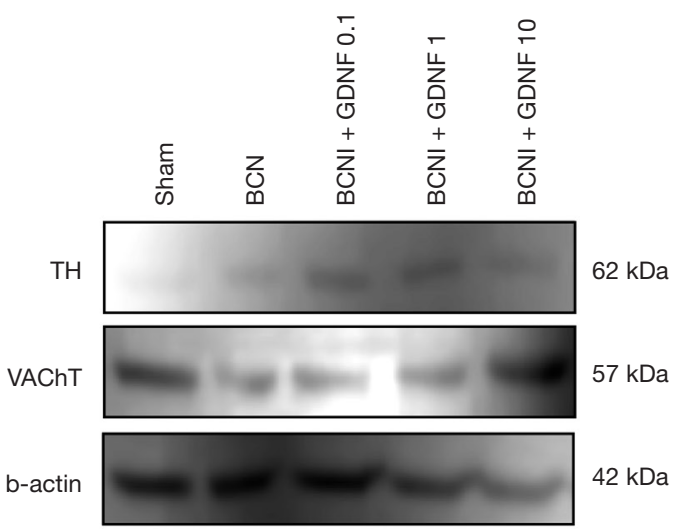

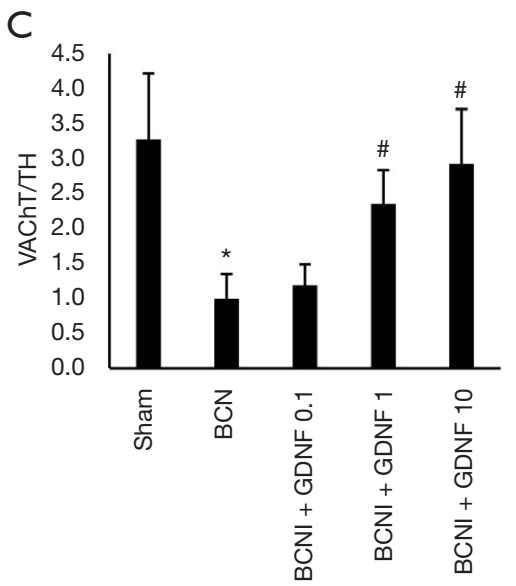

Figure 6 Regrowth of parasympathetic nerve was promoted by GDNF administration. (A) Representative immunofluorescence staining of dorsal nerve of penis for TH and VAChT. Original magnification is 400x. (B) Representative image of Western blot for TH and VAChT in penile tissue. (C) Western blot analysis of TH and VAChT ( $\mathrm{n}=6$ each). Data are presented as mean \pm STD. BCNI, bilateral cavernous nerve injury; GDNF, glial cell derived neurotrophic factor; TH, tyrosine hydroxylase; VAChT, vesicular acetylcholine transporter; DAPI, 40,6-diamidino-2-phenylindole. *, $\mathrm{P}<0.05$ compared to Sham; ${ }^{*}, \mathrm{P}<0.05$ compared to BCNI.

usually follow erection are however mainly controlled by the activity of sympathetic and motor nerves (24). In this project, BCNI animal model was used to mimic the postprostatectomy nerve injury which usually involves damage to both parasympathetic and sympathetic nerve fibers. Both BCNI and GDNF administration showed no influence on sexual arousal in this sexually mature animal model as the chasing and mounting were comparable among different groups. Analysis of intromission which is an indicator of erectile function however displayed that BCNI significantly impaired erectile function and GDNF administration improved it. This was also confirmed by the results of ICP recording test. Changes in ejaculation showed similar trends as with intromission. The higher percentage of rats with T-P+ (might indicate early ejaculation) in BCNI group however, indirectly reflected the potentially "over-active" 
sympathetic tone in these rats.

Based on the present results and results from our previous studies (11), parasympathetic nerve fibers regrowth much slower than sympathetic nerve fibers. The latter own robust regeneration ability themselves even without any interventions which often results in sympathetic overgrowth and autonomic imbalance. According to the histological studies, complete or even more sympathetic $(\mathrm{TH}+)$ nerve fibers regrowth in DNP could be found 4 weeks after BCNI compared to Sham group. The regeneration of parasympathetic $(\mathrm{VAChT}+)$ nerve fibers was significantly impaired after BCNI if no interventions were applied. GDNF as a neurotrophic factor (NTF) was introduced in this study with the expectation to promote autonomic balance recovery during the nerve regeneration process. More MPG originated cavernous nerve fibers nourished by GDNF administration could be found along the urethral tissue. In DNP, the ratio of parasympathetic tone to sympathetic tone was partially recovered by GDNF treatment in a dose dependent manner.

NTF has neural differentiation and neuroprotective effects (25). They themselves hold great therapeutic potential for diseases associated with nerve injury or degeneration (26). Meanwhile, other potential treatment modalities such as the low energy shock wave therapy $(3,12)$ and stem cells products $(5,13)$ have been shown to play their role at least partially through the paracrine of NTFs $(5,8)$. Among all these NTFs, GDNF family consisting of GDNF, neurturin (NTN), artemin (ARTN), and persephin (PSPN) which mainly binds to different GDNF receptors (GFR $\alpha 1-4)$ has already been proven to be vital for the differentiation, regeneration, and maintenance of pelvic parasympathetic system (27). In the newborn mice, GFR $\alpha 1$ is mainly expressed by the non-TH nerve fibers (mainly composed of parasympathetic neurons) (28); partially knockdown of GFR 22 has been shown to impair the parasympathetic innervation in the mice penile tissue, but the development of sympathetic network was not affected $(14,29)$; GFR activation might be beneficial for penisprojecting parasympathetic neurons regeneration (30-32) and the expression of GFR $\alpha$ mRNA has been proven to be closely related to the expression of neuronal nitric oxide synthase (nNOS, a marker for a special kind of parasympathetic nerve, some researchers prefer to classify nNOS+ neuron to Non-adrenergic non-cholinergic neuron or NANC neuron, Figure 5C) following BCNI (33). In fact, there are profound changes within MPG after nerve injury. Sprouting axons occurs concurrently with structural or chemical changes raises the possibility of the formation of aberrant synaptic connections resulting in broader effects on the pelvic autonomic circuitry (14). These structural changes are usually accompanied by changes in NTF signaling, such as altered expression of GDNF or GFRs $(34,35)$. In this project, we demonstrated the dynamic changes of Ntrk1, GFR $\alpha 1$, and GFR $\alpha 2$ associated with BCNI and GDNF treatment. The expression of GFR $\alpha 1$ which is the direct receptor for GDNF had a relatively higher expression level at GDNF concentration of $1 \mu \mathrm{g} / 100$ $\mu \mathrm{L}$. This could be explained by the overlying manifestation of more parasympathetic regrowth and negative feedback between GDNF and its receptor (less amount of receptor is needed when the NTF concentration is higher). But the precise "inflection point" should be investigated in the future as we only examined 4 different concentrations of GDNF in the present study. The amount of Ntrk1 and GFR $\alpha 2$ however directly reflected the regrowth status of sympathetic or parasympathetic nerves which was corresponding to our histological studies.

One of the obstacles that prevent the use of NTFs in clinical scenario is that rapidly degraded NTFs need to be frequently delivered (36). Although a single injection of NTFs might be able to improve neural survival, this effect did not last for a long time (34). Alternative options of NTFs delivery such as multiple injections (37), more stable dissolved solution (37), viral-mediated or cell-based mediated delivery (38-40) are being extensively studied. The concentration of NTFs is a vital parameter for therapeutic effects and should be calculated precisely (41). In the adult human brain, GDNF is expressed at very low levels (43$70 \mathrm{pg} / \mathrm{mg}$ protein at most) (42). The average concentrations of GDNF in cerebrospinal fluid (CSF) and serum are around 218.7 and $711.5 \mathrm{pg} / \mathrm{mL}$ respectively in healthy human beings (43). In a previous study by Kim et al. (44), GDNF was infused intracerebroventricularly continuously at a rate of $8.35 \mathrm{ng} / 0.5 \mathrm{microl} / \mathrm{hour}$ ( $200 \mathrm{ng} /$ day) for 7 days in a rat model of traumatic brain injury, so the GDNF totally administrated was at least $1.4 \mu \mathrm{g} / \mathrm{rat}$. In another study related to Intracerebroventricularly administration of GDNF, 1-5 $\mu \mathrm{g}$ of GDNF was injected one time into the right lateral cerebral ventricle in a rat model (45). Given the fact that the average volume of CSF in adult SD rats is around $90 \mu \mathrm{L}(46)$, the administered GDNF concentration is $11.1-55.6 \mathrm{ng} / \mu \mathrm{L}$ in the above mentioned experiments. However, the continuous infusion technique might be superior than the one-time-shot technique due to the short half-life of GDNF. Although hard to measure, 
rats typically have at least $200 \mu \mathrm{L}$ peritoneal fluid (47), so the total amount of GDNF administered in our study is around 0.018 to $1.8 \mathrm{pg} / \mathrm{mL} / \mathrm{d}$. The average concentrations of GDNF measured in PLF at the end of the experiment did show a dose dependent manner related to the total administrated GDNF amount, however, we did not see any significant differences of GDNF concentrations in serum among groups indicating little permeability of GDNF across bio-membranes under physiological conditions. We assumed that the administrated GDNF mainly played its role locally in the peritoneal or pelvic cavity (40). The continuously released GDNF from osmotic pump bound to the GFR $\alpha 1$ expressed in MPG and cavernous nerve to form a favorable local environment for parasympathetic regeneration for up to 4 weeks which finally resulted in improvements of autonomic balance, erectile function and sexual performance in rats.

\section{Conclusions}

Local continuous GDNF delivery technique promotes parasympathetic nerve fiber regeneration, autonomic balance rehabilitation and sexual function recovery in a rat model of BCNI induced ED. The overexpression of Ntrk1 after BCNI is not influenced by GDNF. The expression of GDNF family receptor $\alpha 1$ in MPG is partially promoted by GDNF administration.

\section{Acknowledgments}

Funding: This work was supported by the National Natural Science Foundation of China (No. 81701434).

\section{Footnote}

Reporting Checklist: The authors have completed the ARRIVE reporting checklist. Available at http://dx.doi. org/10.21037/tau-20-1110

Data Sharing Statement: Available at http://dx.doi. org/10.21037/tau-20-1110

Peer Review File: Available at http://dx.doi.org/10.21037/ tau-20-1110

Conflicts of Interest: All authors have completed the ICMJE uniform disclosure form (available at http://dx.doi. org/10.21037/tau-20-1110). The authors have no conflicts of interest to declare.

Ethical Statement: The authors are accountable for all aspects of the work in ensuring that questions related to the accuracy or integrity of any part of the work are appropriately investigated and resolved. Experiments were performed under a project license (No.: 201875) granted by institutional ethics board of animal care and use committee of Peking university first hospital, in compliance with national guidelines for the care and use of animals.

Open Access Statement: This is an Open Access article distributed in accordance with the Creative Commons Attribution-NonCommercial-NoDerivs 4.0 International License (CC BY-NC-ND 4.0), which permits the noncommercial replication and distribution of the article with the strict proviso that no changes or edits are made and the original work is properly cited (including links to both the formal publication through the relevant DOI and the license). See: https://creativecommons.org/licenses/by-nc-nd/4.0/.

\section{References}

1. Porst H, Burnett A, Brock G, et al. SOP conservative (medical and mechanical) treatment of erectile dysfunction. J Sex Med 2013;10:130-71.

2. Penson DF, Latini DM, Lubeck DP, et al. Do impotent men with diabetes have more severe erectile dysfunction and worse quality of life than the general population of impotent patients? Results from the Exploratory Comprehensive Evaluation of Erectile Dysfunction (ExCEED) database. Diabetes Care 2003;26:1093-9.

3. Li H, Matheu MP, Sun F, et al. Low-energy Shock Wave Therapy Ameliorates Erectile Dysfunction in a Pelvic Neurovascular Injuries Rat Model. J Sex Med 2016;13:22-32.

4. Campbell JD, Burnett AL. Neuroprotective and Nerve Regenerative Approaches for Treatment of Erectile Dysfunction after Cavernous Nerve Injury. Int J Mol Sci 2017;18:1794.

5. Kim SW, Zhu GQ, Bae WJ. Mesenchymal Stem Cells Treatment for Erectile Dysfunction in Diabetic Rats. Sex Med Rev 2020;8:114-21.

6. Krishnan R, Katz D, Nelson CJ, et al. Erectile function recovery in patients after non-nerve sparing radical prostatectomy. Andrology 2014;2:951-4. 
7. Lei H, Liu J, Li H, et al. Low-intensity shock wave therapy and its application to erectile dysfunction. World J Mens Health 2013;31:208-14.

8. Liu MC, Chang ML, Wang YC, et al. Revisiting the Regenerative Therapeutic Advances Towards Erectile Dysfunction. Cells 2020;9:1250.

9. Ryu JK, Suh JK, Burnett AL. Research in pharmacotherapy for erectile dysfunction. Transl Androl Urol 2017;6:207-15.

10. Wang L, Sanford MT, Xin Z, et al. Role of Schwann cells in the regeneration of penile and peripheral nerves. Asian J Androl 2015;17:776-82.

11. Lin G, Li H, Zhang X, et al. Novel therapeutic approach for neurogenic erectile dysfunction: effect of neurotrophic tyrosine kinase receptor type 1 monoclonal antibody. Eur Urol 2015;67:716-26.

12. Lu Z, Lin G, Reed-Maldonado A, et al. Low-intensity Extracorporeal Shock Wave Treatment Improves Erectile Function: A Systematic Review and Meta-analysis. Eur Urol 2017;71:223-33.

13. Xu Y, Guan R, Lei H, et al. Therapeutic potential of adipose-derived stem cells-based micro-tissues in a rat model of postprostatectomy erectile dysfunction. J Sex Med 2014;11:2439-48.

14. Palma CA, Keast JR. Structural effects and potential changes in growth factor signalling in penis-projecting autonomic neurons after axotomy. BMC Neurosci 2006;7:41.

15. Dyachuk V, Furlan A, Shahidi MK, et al. Neurodevelopment. Parasympathetic neurons originate from nerve-associated peripheral glial progenitors. Science 2014;345:82-7.

16. Espinosa-Medina I, Outin E, Picard CA, et al. Neurodevelopment. Parasympathetic ganglia derive from Schwann cell precursors. Science 2014;345:87-90.

17. Toshida H, Suto C. Preganglionic Parasympathetic Denervation Rabbit Model for Innervation Studies. Cornea 2018;37 Suppl 1:S106-12.

18. Forrest SL, Payne SC, Keast JR, et al. Peripheral injury of pelvic visceral sensory nerves alters GFR $\alpha$ (GDNF family receptor alpha) localization in sensory and autonomic pathways of the sacral spinal cord. Front Neuroanat 2015;9:43.

19. Glebova NO, Ginty DD. Heterogeneous requirement of NGF for sympathetic target innervation in vivo. J Neurosci 2004;24:743-51.

20. Fazio L, Brock G. Erectile dysfunction: management update. Cmaj 2004;170:1429-37.

21. Phé V, Rouprêt M. Erectile dysfunction and diabetes: a review of the current evidence-based medicine and a synthesis of the main available therapies. Diabetes Metab 2012;38:1-13.

22. Roppolo JR, Nadelhaft I, de Groat WC. The organization of pudendal motoneurons and primary afferent projections in the spinal cord of the rhesus monkey revealed by horseradish peroxidase. J Comp Neurol 1985;234:475-88.

23. Thor KB, Morgan C, Nadelhaft I, et al. Organization of afferent and efferent pathways in the pudendal nerve of the female cat. J Comp Neurol 1989;288:263-79.

24. Mas M. An update on ejaculation physiology and premature ejaculation definition, prevalence data, and etiology. Semergen 2014;40 Suppl 3:3-10.

25. May F, Buchner A, Schlenker B, et al. Schwann cellmediated delivery of glial cell line-derived neurotrophic factor restores erectile function after cavernous nerve injury. Int J Urol 2013;20:344-8.

26. Wang J, Hu WW, Jiang Z, et al. Advances in treatment of neurodegenerative diseases: Perspectives for combination of stem cells with neurotrophic factors. World J Stem Cells 2020;12:323-38.

27. Stewart AL, Anderson RB, Kobayashi K, et al. Effects of NGF, NT-3 and GDNF family members on neurite outgrowth and migration from pelvic ganglia from embryonic and newborn mice. BMC Dev Biol 2008;8:73.

28. Young HM, Cane KN, Anderson CR. Development of the autonomic nervous system: a comparative view. Auton Neurosci 2011;165:10-27.

29. Forrest SL, Osborne PB, Keast JR. Characterization of axons expressing the artemin receptor in the female rat urinary bladder: a comparison with other major neuronal populations. J Comp Neurol 2014;522:3900-27.

30. Laurikainen A, Hiltunen JO, Thomas-Crusells J, et al. Neurturin is a neurotrophic factor for penile parasympathetic neurons in adult rat. J Neurobiol 2000;43:198-205.

31. Laurikainen A, Hiltunen JO, Vanhatalo S, et al. Glial cell line-derived neurotrophic factor is expressed in penis of adult rat and retrogradely transported in penile parasympathetic and sensory nerves. Cell Tissue Res 2000;302:321-9.

32. Bella AJ, Fandel TM, Tantiwongse K, et al. Neurturin enhances the recovery of erectile function following bilateral cavernous nerve crush injury in the rat. J Brachial Plex Peripher Nerve Inj 2007;2:5.

33. Hisasue S, Kato R, Kobayashi K, et al. Alteration of glial cell line-derived neurotrophic factor family receptor alpha-2 mRNA expression and its co-expression with 
neuronal nitric oxide synthase in pelvic ganglia following unilateral cavernous nerve injury. Int J Urol 2008;15:82-6.

34. Afarid M, Namvar E, Sanie-Jahromi F. Diabetic Retinopathy and BDNF: A Review on Its Molecular Basis and Clinical Applications. J Ophthalmol 2020;2020:1602739.

35. Hannan JL, Albersen M, Stopak BL, et al. Temporal changes in neurotrophic factors and neurite outgrowth in the major pelvic ganglion following cavernous nerve injury. J Neurosci Res 2015;93:954-63.

36. Kotzbauer PT, Holtzman DM. Expectations and challenges in the therapeutic use of neurotrophic factors. Ann Neurol 2006;59:444-7.

37. Marticorena J, Romano V, Gómez-Ulla F. Sterile endophthalmitis after intravitreal injections. Mediators Inflamm 2012;2012:928123.

38. Guy J, Qi X, Muzyczka N, et al. Reporter expression persists 1 year after adeno-associated virus-mediated gene transfer to the optic nerve. Arch Ophthalmol 1999;117:929-37.

39. Park HY, Kim JH, Sun Kim H, et al. Stem cell-based delivery of brain-derived neurotrophic factor gene in the rat retina. Brain Res 2012;1469:10-23.

40. d'Anglemont de Tassigny X, Pascual A, López-Barneo J. GDNF-based therapies, GDNF-producing interneurons, and trophic support of the dopaminergic nigrostriatal pathway. Implications for Parkinson's disease. Front

Cite this article as: Li H, Zhang Z, Fang D, Tang Y, Peng J. Local continuous glial cell derived neurotrophic factor release using osmotic pump promotes parasympathetic nerve rehabilitation in an animal model of cavernous nerve injury induced erectile dysfunction. Transl Androl Urol 2021;10(1):258271. doi: $10.21037 /$ tau-20-1110
Neuroanat 2015;9:10

41. Khalin I, Alyautdin R, Kocherga G, et al. Targeted delivery of brain-derived neurotrophic factor for the treatment of blindness and deafness. Int J Nanomedicine 2015;10:3245-67.

42. Luz M, Mohr E, Fibiger HC. GDNF-induced cerebellar toxicity: A brief review. Neurotoxicology 2016;52:46-56.

43. Straten G, Eschweiler GW, Maetzler W, et al. Glial cellline derived neurotrophic factor (GDNF) concentrations in cerebrospinal fluid and serum of patients with early Alzheimer's disease and normal controls. J Alzheimers Dis 2009;18:331-7.

44. Kim BT, Rao VL, Sailor KA, et al. Protective effects of glial cell line-derived neurotrophic factor on hippocampal neurons after traumatic brain injury in rats. J Neurosurg 2001;95:674-9.

45. Sharma HS, Johanson CE. Intracerebroventricularly administered neurotrophins attenuate blood cerebrospinal fluid barrier breakdown and brain pathology following whole-body hyperthermia: an experimental study in the rat using biochemical and morphological approaches. Ann N Y Acad Sci 2007;1122:112-29.

46. Pardridge WM. Drug transport in brain via the cerebrospinal fluid. Fluids Barriers CNS 2011;8:7.

47. Padawer J, Gordon AS. Cellular elements in the peritoneal fluid of some mammals. Anat Rec 1956;124:209-22. 


\section{Supplementary}

A

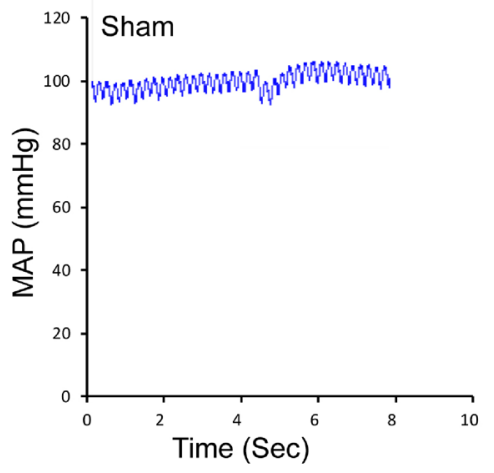

D

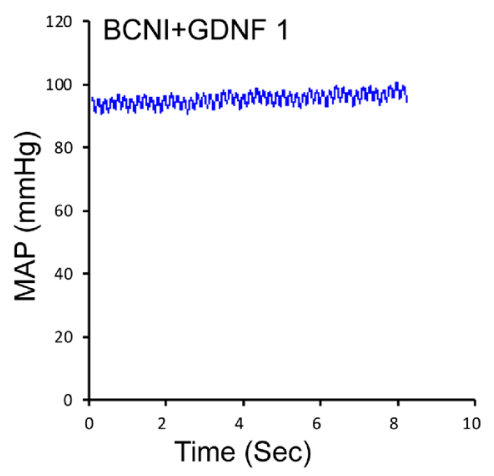

B

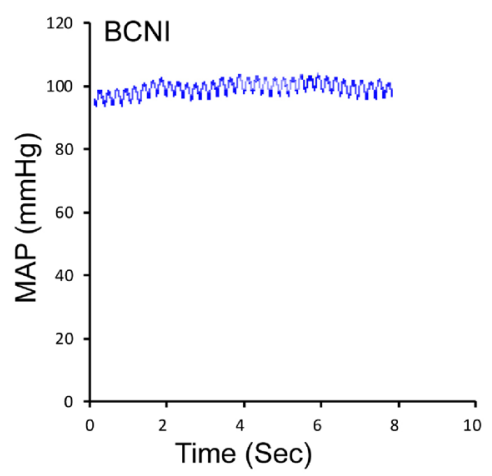

$E$

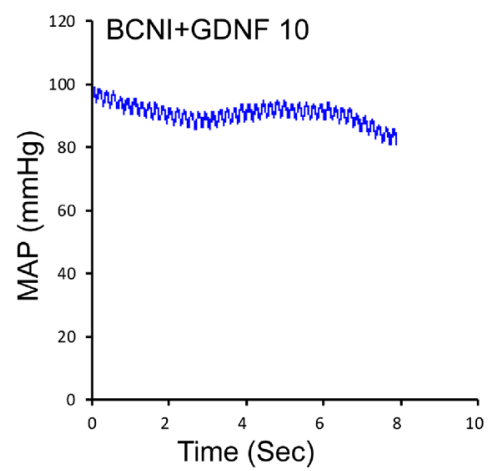

C

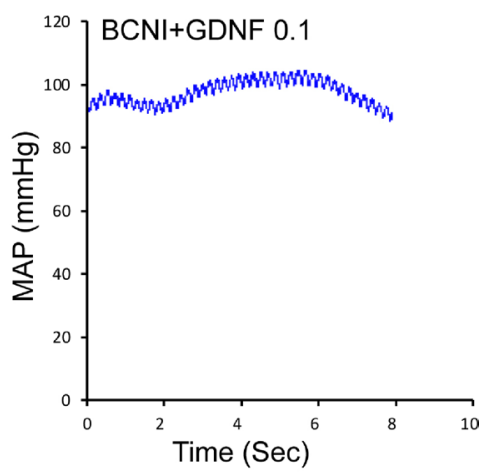

Figure S1 (A-E) Representative MAP recordings for the experimental groups of Sham (A, n=8), BCNI (B, n=7), BCNI+GDNF 0.1 (C, $\mathrm{n}=7), \mathrm{BCNI}+\mathrm{GDNF} 1(\mathrm{D}, \mathrm{n}=8), \mathrm{BCNI}+\mathrm{GDNF} 10$ (E, n=8). MAP, mean arterial pressure. 